\title{
Obstáculos e potencialidades da participação social em Conselhos Distritais de Saúde do município de João Pessoa-PB
}

\section{Obstacles and potentials of social participation in District Health Councils of João Pessoa-PB}

\author{
Ana Paula Maia Espíndola Rodrigues ${ }^{\star}$ \\ Ione Gomes da Silva* \\ Pedro José Santos Carneiro Cruz ${ }^{* \star *}$
}

\begin{abstract}
Resumo: O presente artigo analisa a participação social nos Conselhos Distritais de Saúde (CDS) da cidade de João Pessoa-PB, evidenciando suas dificuldades e potencialidades. Resultou de uma investigação com abordagem qualitativa, cuja operacionalização se deu em duas etapas, respectivamente: entrevistas individuais e observação participante. Foram realizadas entrevistas individuais semiestruturadas, organizadas em um roteiro e aplicadas com os diretores gerais e/ou técnicos/profissionais dos Distritos Sanitários (DS). Decorreram participações em reuniões mensais destes conselhos, com sistematização do olhar do pesquisador via diário de campo. A perspectiva de análise desenvolvida no decorrer desta pesquisa consistiu-se da dialética. Os resultados demostram que o principal obstáculo, na visão dos membros dos DS, consiste na participação dos usuários nas reuniões. Muitos dos movimentos e das entidades com potencial de participação não se fazem presentes nesse espaço por não acreditarem que tal participação seja capaz de gerar mudanças. Palavras-chave: Participação social. Conselhos de Saúde. Sistemas Locais de Saúde.
\end{abstract}

\begin{abstract}
This article analyzes the social participation in the district health councils (cds) of the city of joão pessoa-pb, highlighting its difficulties and potentialities. It was the result of an investigation with a qualitative approach, whose operation took place in two stages, respectively: individual interviews
\end{abstract}

\footnotetext{
*Especialista em Saúde da Família pela Secretaria de Saúde do Jaboatão dos Guararapes - PE; Especialista em Nutrição Esportiva pela Faculdade Integrada de Patos; Graduada em Nutrição pela Universidade Federal da Paraíba; E-mail: anapaulaespindola@hotmail.com.

** Mestre em Educação pelo Programa de Pós-Graduação em Educação da Universidade Federal da Paraíba; Graduada em Pedagogia pela Universidade Federal da Paraíba; E-mail: ionegs89@gmail.com.

*** Doutor em Educação pelo Programa de Pós-Graduação em Educação da Universidade Federal da Paraíba; Mestre em Educação pela Universidade Federal da Paraíba; Graduado em Nutrição pela Universidade Federal da Paraíba; Professor do Departamento de Promoção da Saúde do Centro de Ciências Médicas da Universidade Federal da Paraíba. E-mail: pedrojosecruzpb@yahoo.com.br.
} 
and participant observation. Semi-structured individual interviews were conducted, organized in a script and applied with the general directors and / or technicians / professionals of the Health Districts (DS). Monthly meetings of these councils were held, by systematizing the look of the researcher via field diary. The perspective of analysis developed during this research consisted of dialectic. The results show that the main obstacle, in the view of the members of the DS, is the participation of users in the meetings. Many of the movements and entities with potential participation are not present in this space because they do not believe that such participation is capable of generating change.

Keywords: Social Participation. Health Councils. Local Health Systems.

Recebido em 16/12/2019. Aceito em 11/11/2020

\section{Introdução}

No debate sobre a participação social em saúde, a análise da dinâmica de funcionamento dos conselhos constitui uma preocupação fundamental, no sentido de vislumbrar lacunas em seus processos de construção - que são sempre dinâmicos e multifacetados -, e, então, poder-se priorizar o aprimoramento desses espaços institucionais de participação.

Por este caminho, podem-se construir conhecimentos para dar visibilidade aos desafios e às situações-limite colocadas no processo de elaboração de políticas públicas e no controle das ações em saúde exercidas. Assim, vislumbrando-se a possibilidade de identificar os problemas existentes nos âmbitos interno e externo ao conselho, de modo a propor intervenções que possam contribuir para a melhoria das condições de vida e saúde da população, incorrendo no fortalecimento do sistema sanitário.

A Lei 8.142, de 28 de dezembro de 1990, indica as competências dos Conselhos de Saúde (CS) e, em seu art. 1ำ § 2º define-os como “[...] órgão colegiado composto por representantes do governo, prestadores de serviço, profissionais de saúde e usuários [...]." Como mecanismos que permitem a participação social, os conselhos de saúde constituem-se como elementos importantes na construção da cidadania, sendo ainda apontados como instrumentos de controle social que, de forma estratégica, podem assegurar o direito à saúde (MARTINS et al., 2008).

Conforme Labra (2005), os conselhos de saúde são enxergados como estratégias institucionais que têm o objetivo de abrir as portas do setor da saúde para a participação dos cidadãos; mas, além disso, podem, também, contribuir para propagar a cultura participativa, tão comum em uma comunidade cívica. Esses espaços institucionalizados são de fundamental importância para que a população possa ter vez e voz na gestão das políticas públicas, estimulando sua autonomia como protagonista e cidadãos comprometidos e participativos com o bem-estar da sociedade (GOHN, 2001; ALENCAR; CRUZ, 2013).

De acordo com Kruger (2000, p. 122), “o espaço dos conselhos comporta conflitos, resistências e tensões permanentes, como também soluções criativas que podem ser combinadas no processo de apropriação social dos espaços públicos", de modo a propor intervenções que possam contribuir para a melhoria das condições de vida e de saúde da população, visando, assim, 
ao fortalecimento do sistema sanitário. Como instrumentos úteis e privilegiados, os conselhos de saúde podem facilitar o acesso dos sujeitos aos seus direitos, uma vez que, através dessas instituições, as tradicionais formas de gestão sofrem rompimento, dando lugar a espaços de decisão e ação do poder público e incentivando a criação de ambientes mais democráticos para a construção de uma cultura política mais participativa (KRUGER, 2000).

O presente artigo tem por objetivo enfocar a participação social nos Conselhos Distritais de Saúde (CDS), suas dificuldades e potencialidades na cidade de João Pessoa, Paraíba, Brasil. Resultou de um estudo construído com base na inserção dos pesquisadores no processo de desenvolvimento de um conselho local de uma Unidade de Saúde da Família (USF), por meio do Programa de Extensão Universitária Práticas Integrais de Promoção da Saúde e Nutrição na Atenção Básica (PINAB) da Universidade Federal da Paraíba (UFPB).

\section{Métodos}

O lócus do estudo consistiu-se dos CDS(s) da cidade de João Pessoa, a qual se encontra demarcada territorialmente por cinco Distritos Sanitários (DS), com o objetivo de organizar a rede de cuidado progressivo do sistema e garantir à população o acesso aos serviços oferecidos pelos três níveis de complexidade do Sistema Único de Saúde (SUS). As reuniões de cada CDS ocorrem com as equipes de saúde de cada distrito e suas respectivas comunidades do território e têm a intencionalidade de potencializar a participação social.

Este estudo possui abordagem qualitativa, envolvendo, conforme fundamentado por Gadamer (1999), a busca de compreensão dos sentidos e, como ressalta Minayo (2008), a valorização dos contextos pesquisados, bem como os significados, valores e as atitudes intervenientes (CAMARGO JR; BOSI, 2011).

Sua operacionalização deu-se em três etapas, respectivamente: pesquisa documental, entrevistas individuais e observação participante, que pode ser caracterizada pelo contato direto do pesquisador com o fenômeno estudado (MINAYO, 2008). Na primeira etapa, houve coleta de dados acerca do funcionamento, composição e pautas dos conselhos distritais de saúde, através de visitas aos cinco Distritos Sanitários de João Pessoa - PB e aos seus respectivos conselhos, sendo, então, informações levantadas, registradas e organizadas através de um roteiro. Na segunda etapa, foram realizadas entrevistas individuais semiestruturadas, também organizadas em um roteiro e aplicadas com os diretores-gerais e/ou técnicos/profissionais dos Distritos Sanitários. Quanto à terceira etapa, decorreram participações dos pesquisadores em reuniões mensais destes conselhos. A coleta de dados deu-se no período de outubro de 2015 a maio de 2016.

$\mathrm{Na}$ etapa de pesquisa documental, foi desenvolvido um mapeamento das experiências de conselho distrital em saúde no município de João Pessoa, a partir das atas das reuniões dos Conselhos Distritais de Saúde. Foram realizadas, inicialmente, visitas às regiões de saúde da cidade, visando articular informações básicas com os cinco Distritos Sanitários quanto ao funcionamento de cada conselho, bem como identificar agendas de reuniões e contatos dos membros, inclusive do presidente. Para registro destas e outras informações, foi adotado um roteiro, que foi respondido pelos profissionais do local, quando de sua visita, com as seguintes categorias de informações: 1) Distrito Sanitário; 2) Data da última reunião do Conselho Distrital; 3) Composição do Conselho Distrital; 4) Presidência e Vice-Presidência; 5) Data de fundação do Conselho; 6) Número de reuniões desde a fundação do Conselho; 7) Pautas das últimas cinco reuniões do Conselho. 
As entrevistas foram promovidas com diretores gerais e técnicos dos 5 DS, totalizando 5 entrevistas, 1 para cada DS. Essa técnica de coleta de dados correspondeu à combinação de perguntas abertas e fechadas, onde o informante teve a possibilidade de discorrer sobre o tema proposto. Além disso, este tipo de entrevista permitiu a adição de perguntas relativas ao estudo para elucidar questões que não ficaram claras ou ajudar a recompor o contexto da entrevista. Com isso, permitiu-se identificar, de maneira mais precisa, a percepção que os participantes possuem sobre o tema, com o intuito de garantir a elaboração do pensamento e as reflexões por parte dos sujeitos da pesquisa.

$\mathrm{Na}$ entrevista, foram abordados assuntos referentes à percepção dos profissionais ou Gestores sobre o funcionamento dos CDS(s), a partir de um roteiro com as seguintes categorias de informação: 1) Como funciona o CDS?; 2) Pontos positivos e negativos; 3) Há conselho local na cobertura territorial do DS?; 4) Quantos existem?; 5) As reuniões do CDS acontecem? Onde?; 6) Há paridade? Quem participa?; 7) Quais as estratégias do DS para uma gestão participativa?; 8) Quais Movimentos sociais fazem parte do distrito?

Por meio da observação, houve participações dos pesquisadores em reuniões dos CDS(s) da cidade, com sistematização do olhar do pesquisador via diário de campo, gerando registros reflexivos sobre alguns dos aspectos da dinâmica do funcionamento dos mesmos. A observação foi livre, sem roteiro específico, abrangendo centralmente aspectos como: a dinâmica de funcionamento do conselho distrital, suas lacunas e potenciais, bem como o relacionamento entre seus componentes e suas formas de atuação e intervenção. Para tanto, inicialmente, foi propiciada a inserção dos pesquisadores em reuniões de cada um dos cinco CDS(s) de João Pessoa. Porém, só foi possível a participação em duas delas, uma vez que, no ano de 2016, as eleições para conselheiros distritais estavam atrasadas e, por isso, as reuniões mensais não estavam acontecendo em alguns dos conselhos. Segundo os próprios entrevistados, a nova eleição deveria ter ocorrido em Setembro de 2015 e acompanhada pelo Conselho Municipal de Saúde (CMS), que também estava em processo eleitoral.

A perspectiva de análise desenvolvida no decorrer desta pesquisa consistiu da dialética. Como afirma Holliday (1996), a concepção metodológica dialética é uma maneira de conceber a realidade, de aproximar-se dela para conhecê-la e de atuar sobre ela para transformá-la. Assim, podemos considerar a dialética como um modo de analisar a realidade, considerando-a em sua essência contraditória e em permanente transformação (MELO NETO, 1996). Optamos pela dialética marxista, que parte do real através de movimentos profundos de reflexão direcionados para a revelação da verdade, ou mesmo da elevação crítica da consciência sobre esta realidade (MARKUS, 1974, citado por MELO NETO, 2002).

A participação dos sujeitos no estudo foi voluntária mediante assinatura do Termo de Consentimento Livre e Esclarecido (TCLE), conforme a resolução 466/2012, do Conselho Nacional de Saúde, e o projeto de pesquisa foi aprovado pelo Comitê de Ética do Centro de Ciências da Saúde da Universidade Federal da Paraíba, sob o parecer número 1.554.948. 


\section{Resultados e discussão}

\section{Participação social nos CDS do município de João Pessoa: elementos de análise com base na percepção de gestores}

Quadro 1. Dimensões emergentes de obstáculos e de potencialidades da participação social nos CDS a partir da análise das entrevistas.

\begin{tabular}{|l|l|}
\hline Obstáculos & Potencialidades \\
\hline Dificuldade de participação dos profissionais & Oportunidades de aprendizagem \\
\hline Ênfase individualista da participação & $\begin{array}{l}\text { Criação de espaços coletivos de discussão e reflexão } \\
\text { sobre a realidade }\end{array}$ \\
\hline Fragilidade na participação dos usuários & Empoderamento dos usuários \\
\hline $\begin{array}{l}\text { Escassez de espaços de formação para os } \\
\text { conselheiros }\end{array}$ & $\begin{array}{l}\text { A mobilização coletiva e individual para a criação de } \\
\text { Conselhos Locais }\end{array}$ \\
\hline $\begin{array}{l}\text { Visão pessimista sobre o potencial dos conselhos na } \\
\text { produção de mudanças e na resolução de problemas }\end{array}$ & \\
\hline Pouca frequência de reuniões & \\
\hline
\end{tabular}

Fonte: Elaboração própria com base nos dados da pesquisa.

\section{Obstáculos}

- Dificuldades quanto à quantidade e qualidade na participação de alguns profissionais

Segundo os depoimentos dos sujeitos da pesquisa, alguns membros da sociedade civil têm dificuldades de participarem de forma comprometida nas ações de controle social. Essa dificuldade também é enfrentada em algumas categorias de profissionais como, por exemplo, a médica, uma vez que a maioria de seus representantes não se faz presente nas reuniões dos CDS(s), deixando a cargo apenas dos outros profissionais a função de compor a entidade representativa dos trabalhadores de saúde. Conforme apontam Nogueira et al. (2008), essa tímida participação dos profissionais não está de acordo com o que dispõe a Política Nacional de Atenção Básica, que aponta como "uma das atribuições desses profissionais o papel de indutor na promoção e estímulo à participação da comunidade no controle social, como característica do processo de trabalho [...]" (p. 108).

Em alguns conselhos, a presença quase que exclusiva dos agentes comunitários de saúde e dos enfermeiros é apontada como fragilidade, por revelar pouca interdisciplinaridade e pluralidade de papéis, havendo a persistência da ausência de outras categorias profissionais. Segundo os depoimentos, alguns odontólogos participam das reuniões de alguns conselhos locais, mas não do distrital.

$\mathrm{Na}$ avaliação dos sujeitos da pesquisa, muito dessa fragilidade na participação social se dá, também, por mudanças na configuração dos territórios das unidades de saúde e/ou dos DS. Isso acarreta em mudanças nas configurações dos grupos componentes e também em certa perda da "sintonia" comunicativa construída ao longo do tempo entre alguns profissionais e representantes da sociedade civil que participavam de forma mais ativa.

Entende-se, de acordo com os depoimentos, ser necessário aos membros atuais dos conselhos repensar estratégias para a promoção da participação social, tanto por parte dos profissionais 
quanto pela sociedade civil, como forma de mobilizar novas lideranças comprometidas com a luta por melhorias e o controle social.

Segundo relatado por uma das entrevistadas, outra dificuldade é que o profissional da saúde, muitas vezes, tem resistência em mostrar as particularidades e dificuldades de seu contexto de trabalho para outras pessoas, bem como de discutir as limitações do serviço e as barreiras que existem na comunicação entre o profissional e o usuário. Avalia-se, nos depoimentos, que isso se deve a um receio dos profissionais em evidenciar fragilidades de seu processo de trabalho e, assim, ficarem "vulneráveis" aos olhos dos usuários, abrindo espaços para críticas, reclamações e problematizações, o que não é bem-vindo, pois, de acordo com a percepção de um dos entrevistados, muitas vezes, os profissionais não estão dispostos a escutar e dialogar.

- Ênfase individualista da participação de alguns atores sociais

De acordo com um dos entrevistados, a maioria dos conselheiros representa a si mesmo e a seus interesses, levando ao conselho preponderantemente demandas individuais ou de grupos, entidades ou coletivos específicos:

"Eu acredito que a sociedade deixou de ser organizada para trabalhar o conjunto, $e$ cada um está trabalhando a sua bandeira, cada um segura uma bandeira e só trabalha por ela. Mas esquecem que eu sou mulher, sou negra, posso ser homossexual ou não, posso ter filhos ou não. As pessoas esquecem que uma só pessoa pode segurar todas as bandeiras e ser representante de todas elas" (Entrevistado 1).

Conforme é enfatizado por Coelho (2012, p. 148), "É natural que um conselheiro leve as reivindicações de seus pares, mas estas não podem ser mais importantes que as do conjunto". Segundo outra pessoa entrevistada, os membros que querem resolver apenas as suas próprias demandas acabam deixando de lado o sentimento de coletividade. Segundo ela: "as pessoas deturpam o conselho, não entendem que o benefício é para a coletividade" (Entrevistado 2). Ou seja, optam em participar das reuniões colocando em pauta questões individuais, como marcações de exames, que precisam ser dinamizadas, consultas com um especialista que não conseguiram ser providenciadas ou a disponibilização de medicamentos.

Foi colocado pelo Entrevistado 3 que, nem sempre, a comunidade responde às ações de mobilização utilizadas pela gestão para que a participação popular aconteça, ou mesmo para que seja aprimorada. Pouco comparecem às reuniões de equipe nas USFs, mesmo sendo convidados a ocuparem esse espaço.

Avalia-se que os conselheiros deveriam exercitar a defesa dos interesses do movimento que representam, como forma de diminuir o individualismo e promover a perspectiva da coletividade. Sobre a importância de aprimorar o conhecimento dos usuários, Coelho (2012, p. 146) nos diz o seguinte:

O conhecimento contribui para a tomada de decisões, sem ele não há como a população organizada exercer o seu papel de fiscalizadora e avaliadora dos serviços, e consequentemente de conseguir a melhoria real de sua saúde. Por isso a comunicação está relacionada ao poder, e sua apropriação pelas camadas populares é um importante instrumento de luta contra a hegemonia, retirando a população do papel de refém do saber técnico. 
- Fragilidade na participação dos usuários

Relatou-se nos depoimentos que existe pouco interesse e/ou indisponibilidade de alguns membros da sociedade civil em participar das reuniões de conselho em virtude da falta de remuneração. Para o Entrevistado 3, alguns usuários, por vezes, perguntam se vão receber salário ao participarem do conselho local, o que demonstra, segundo ela "o quanto é difícil tirar o usuário de dentro de sua residência pra discutir problemas de saúde na equipe" (Entrevistado 3). De acordo com Nogueira et al., (2008) em alguns casos, é possível observar entre os usuários uma cultura política pouco participativa, além disso, cada região possui diversas peculiaridades, como interesses políticos opostos, que exercem influência sobre a mobilização social, o que acaba por dificultar o processo de sensibilização das pessoas para a participação nos conselhos.

Tal dificuldade é sentida também nos Conselhos Locais de Saúde (CLS), conforme afirma o Entrevistado 3, uma vez que a própria comunidade não quer, em sua percepção, participar do espaço. Nesse sentido, o Entrevistado 4 acredita que há falta de prioridade desses espaços pelos usuários: "a participação de alguns conselheiros é muito limitada porque eles têm outras atividades, têm seus trabalhos..." (Entrevistado 4). Em vista disso, em sua visão, é necessário que eles percebam a importância do espaço, pois é nele que a gestão pode se tornar participativa e descentralizada, de modo que os usuários possam ter voz enquanto coletivo para propor e cobrar soluções aos problemas efetivamente voltados às suas reais necessidades.

A participação popular deve ser entendida como "as múltiplas ações que diferentes forças sociais desenvolvem para influenciar a formulação, execução, fiscalização e avaliação das políticas públicas e/ou serviços básicos na área social" (VALLA, 1998, p. 9). Desta forma, a participação dos conselheiros e usuários deve ser estimulada, pois é através dela que eles poderão conquistar a concretização das suas demandas. Contudo, é importante ressaltar que, muitas vezes, os profissionais de saúde, gestores e intelectuais não entendem as motivações concretas que levam os usuários a não participar dos espaços de cidadania, apesar da importância que tem essa participação.

- Escassez de espaços de formação para os conselheiros

Nas reuniões das quais os pesquisadores participaram, foi possível observar pouca clareza dos conselheiros sobre questões relativas ao funcionamento do próprio CDS, provavelmente acarretada pela complexidade do funcionamento dos mesmos e pela escassez de espaços de formação permanente para o controle social. Observou-se que, nas reuniões, foram abordados temas formativos, com o intuito de capacitar os membros do conselho quanto à sua proposta $\mathrm{e}$ funcionamento; mas o cotidiano das ações e das atitudes dos conselheiros revela que esses momentos formativos parecem não ser suficientes. Nesse sentido, concordamos com Gohn (2004, p. 28), quando ela afirma que "os conselheiros devem ter formação e consciência crítica, para terem como meta o entendimento do processo onde se inserem [...]".

Há na cidade uma escassez de espaços de formação específicos voltados para os conselheiros, de modo que eles compreendam o papel do conselho, seus objetivos, sua dinâmica funcional e organizativa, bem como questões do aparato legal do SUS etc. Isso pode comprometer a boa atuação do conselho e também do conselheiro, por apenas haver uma ênfase na ocupação de espaço, em detrimento de um aperfeiçoamento permanente na capacidade do conselheiro de se apropriar da dinâmica do conselho, de forma a potencializar sua atuação com autonomia e protagonismo. 
- Visão pessimista sobre o potencial dos conselhos na produção de mudanças e na resolução de problemas

Outra fragilidade identificada foi posta especialmente na fala do Entrevistado 4, que fala sobre a pouca credulidade das pessoas participantes quanto à possibilidade dos CDS(s) de gerar mudanças ou mesmo de resolver os problemas demandados pela sociedade. Tal visão leva a uma tímida participação de alguns conselheiros que preferem participar de forma mais ativa das reuniões dos CLS dentro de seus próprios territórios, à medida que as pactuações e ações promovidas nesse contexto são mais factíveis e ágeis, especialmente por envolverem atores que convivem cotidianamente em um território circunscrito em menor escala e, portanto, cultivam melhor comunicação no sentido de galgarem sucesso nas propostas de mudanças desejadas.

Os entrevistados referem que, no contexto distrital, o processo de busca e de implementação de mudanças é mais demorado e, por vezes, muito difícil, uma vez que envolve um grau substancial de burocracia. Dado que corresponde a um território mais amplo e uma gama maior de atores sociais (muitos deles pouco vinculados entre si), os trâmites precisam ser mais institucionais do que pessoais, e, assim, criam-se vários obstáculos para o equacionamento de algumas questões. No nível local, pactua-se entre pessoas que se conhecem, das quais se podem cobrar cotidianamente, acompanhar as pactuações ou mesmo colaborar.

Por isso, em casos como o do DS IV, em João Pessoa, opta-se pelas reuniões distritais itinerantes, sediadas em pontos estratégicos do território, onde há movimentos e práticas de participação reconhecidas e importantes, como forma de mobilizar os usuários a participarem. Conforme é enfatizado por Aciole:

A visão dos pessimistas repousa na sua desconfiança de posições exageradamente positivas sobre a realidade dos conselhos, ao identificar dificuldades para o seu funcionamento pleno e destacar suas relações com instituições e práticas que, interna e externamente, condicionam e limitam as possibilidades de democratização no SUS. (ACIOLE, 2003, p. 11).

Cabe destacar que, para além de qualquer sentimento de desconfiança ou incredulidade, é preciso levar em conta a possibilidade desse tipo de colegiado em se constituir de forma autônoma, apesar de ser um órgão institucionalizado e, portanto, capaz de gerar mudanças. Ultrapassando, assim, os limites que se impõem para a plenitude do seu funcionamento e expondo o seu potencial transformador (ACIOLE, 2003).

\section{- Pouca frequência de reuniões}

Para o Entrevistado 5, a principal dificuldade encontrada no processo de controle social através dos CDS(s) é o distanciamento entre uma reunião e outra, uma vez que elas acontecem apenas uma vez por mês e, assim, por vezes, a análise e discussão das demandas ficam prejudicadas. Embora que, segundo ele, os CLS dos territórios de alguns DS sejam bastante atuantes e nem sempre seja necessário ocorrer as reuniões do CDS para que demandas importantes de controle social cheguem à gestão. Contudo, entendendo o papel singular dos CDS(s), o entrevistado avalia que reuniões mensais tornam frágil a comunicação entre os protagonistas do conselho. Em sua visão, é preciso estimular o vínculo entre os integrantes como forma de fortalecer esse espaço.

De acordo com a Política Nacional de Atenção Básica (PNAB), o vínculo diz respeito à “[...] construção de relações de afetividade e confiança entre o usuário e o trabalhador da saúde, permitindo o aprofundamento do processo de corresponsabilização pela saúde, construído ao longo do tempo [...]" (BRASIL, 2012, p. 21). A PNAB diz-nos sobre a importância do estabelecimento dos 
vínculos; mas, ao mesmo tempo, vivemos em uma sociedade onde o estabelecimento de vínculos entre as pessoas, de modo geral, é tarefa cada vez mais difícil. Então, faz-se necessário estimular a criação dos mesmos. Assim, acredita-se que é, de fato, importante investir na sistematicidade e na regularidade das reuniões dos Conselhos, pois é preciso criar vínculos entre as pessoas para que elas consigam construir uma comunidade de trabalho, um espaço de discussão e empoderamento.

Além de incentivar o vínculo como principio mediador de uma relação propositiva e construtiva entre os membros do CDS, uma frequência sistemática de reuniões permitiria, paulatinamente, fazer desses espaços comunidades de trabalho, nas quais um grupo de atores sociais se reúne com objetivos comuns e se empenham em processos de construção de trabalhos, produtos e de experiências para a consecução dos referidos objetivos. Dessa maneira, em uma comunidade de trabalho,

pessoas se unem (...) em torno de objetivos comuns que ultrapassam a ordem pessoal, se situam e se enraízam em compromisso com a construção de uma sociedade justa que garanta iguais direitos e tratamento diverso para diferentes condições, circunstâncias. (SILVA; ARAUJO-OLIVERA, 2004, p. 2).

Para Oliveira (2009), nas experiências de ação social caracterizadas pela dimensão das comunidades de trabalho, articulam-se e confrontam-se, em processos de interação subjetiva, grupos de origens e classes distintas, grupos que constroem vínculos afetivos e político-ideológicos, mas, necessariamente, grupos compromissados com a construção do sujeito-cidadão. Mobiliza-se, no agir social e cidadão, uma dimensão que supera o individualismo, pois é coletiva e criada a partir das condições de vida e das necessidades de conjuntos de pessoas.

Uma comunidade de trabalho, nessa acepção, somente pode ser constituída na medida em que seus momentos de encontro se deem com regularidade, de modo que se torne cotidiana a relação entre seus sujeitos e seja possível tecer uma rede de relações, de laços comunicativos e de identidade e reciprocidades suficientes para que se fortaleça uma ideia de grupo e, então, um coletivo com capacidade e potencialidade de operar mudanças significativas diante dos problemas e dos desafios encontrados.

\section{Potencialidades}

- Oportunidades de aprendizagem

A participação sistemática das pessoas nos conselhos leva, necessariamente, a oportunidades de aprendizagem sobre o controle social, sobre a participação popular e sobre os desafios para o aprimoramento do SUS, suas políticas e seus serviços. Apesar de que, como foi escrito anteriormente, ainda é necessário que os conselheiros passem por uma formação permanente. Sendo assim, é de fundamental importância "desencadear processos de qualificações que possibilitem, além do entendimento da estrutura e funcionamento do SUS, uma compreensão ampliada do campo da saúde e da atuação dos conselheiros" (FERNANDES, 2019, p. 25)

De um modo geral, as reuniões e discussão de problemas concretos da dinâmica das políticas de saúde no DS estimulam as pessoas a procurar ampliar seus conhecimentos, por exemplo, a respeito do funcionamento do sistema e das dificuldades em concretizar as ações de saúde em meio aos desafios burocráticos e administrativos postos na gestão e na operação do Sistema Único de Saúde. 
Outro aspecto relevante é que os encontros humanos propiciados pelas reuniões podem favorecer processos de comunicação e de compartilhamento de saberes, práticas e experiências, nos quais cada uma das três categorias que participam dos conselhos - gestores, trabalhadores e usuários - pode compreender as particularidades do lugar de cada um e dos desafios. A presença qualificada dos cidadãos nos espaços dos CDS e dos CLS contribuem para a melhoria e afirmação da gestão participativa das políticas públicas de saúde. Os sujeitos começam a perceber que os seus problemas estão na esfera do micro, e que há forças poderosas atuando na esfera do macro.

- Criação de espaços coletivos de discussão e reflexão sobre a realidade

De acordo com uma das pessoas entrevistadas, em um dos bairros de João Pessoa, os membros do CLS procuram problematizar e entender a raiz do problema discutido e as possíveis formas de resolvê-lo. Segundo o Entrevistado 1, "eles não olham apenas de forma superficial as questões elencadas. Se está faltando luva, por exemplo, a luva vem de onde? Quem solicita? Se é a secretaria, então a solicitação tem que ser feita diretamente à secretaria." E, dessa forma, vão buscando alternativas para as pautas trazidas pelos membros.

Um ponto positivo citado pela Entrevistada 2 foi que, quando efetiva, a participação popular nos CDS(s) desenvolve um nível importante de envolvimento da comunidade no enfrentamento das questões de saúde e na construção de ações de promoção e de prevenção. Permite-se, dessa forma, constituir um agir em saúde de forma mais aproximada às demandas tanto do serviço quanto do usuário. Ou seja, caso exista alguma limitação à prestação do serviço de saúde, a comunidade será esclarecida acerca do motivo pelo próprio serviço, e, do mesmo modo, caso a comunidade tenha alguma demanda, os gestores buscarão alternativas para solucionar tais questões: "a gestão, junto com os comunitários, busca as resoluções para as demandas apresentadas" (Entrevistado 2).

Mesmo não acontecendo em um volume significativo, quando acontece, a participação de membros da comunidade nos CDS(s) ocorre com uma significativa qualidade e contribui para adequar as demandas do SUS à realidade comunitária e também para gerar processos de entendimento, de diálogo e de comunicação propositiva entre os usuários e gestores. O usuário traz a pauta referente ao seu território e sai da reunião mais empoderado sobre o que reivindicar, a que órgãos reivindicar e apto a contribuir com essas informações no seu território. Pois, conforme Coelho:

A participação é determinante fundamental da democracia. Não é concessão nem exigência burocrática, mas uma conquista social. Participação plena significa decidir, acompanhar e avaliar a organização dos serviços, ou seja, exercer o controle social. Ela se constitui de forma politizada e permite que um coletivo decida sobre assuntos de interesse geral. Assim, as diferentes realidades da população podem ser contempladas na construção de políticas. (COELHO, 2012, p. 145).

Segundo o Entrevistado 5, a motivação dos usuários em participar dos movimentos locais é vista como uma potencialidade, assim como dos agentes comunitários de saúde, que "embora em reduzida quantidade, possuem determinação, gostam de trabalhar com o povo e querem mudança". Em um dos CDS(s), do qual o entrevistado 5 participa, quando a pauta está diretamente relacionada à saúde, os gestores procuram alternativas para solucioná-las; quando não está, a gestão encaminha as demandas para os responsáveis. Porém, assuntos mais urgentes não necessariamente precisam esperar para a reunião do CDS, uma vez que alguns CLS se reúnem e levam demandas diretamente para que a gestão busque as resolutividades. 
Portanto, ficou claro pela fala da pessoa entrevistada que a participação popular em determinados territórios do DS em questão é efetiva, visto que a sociedade civil está mobilizada a participar ativamente nas discussões de saúde e a busca por melhorias dentro dos conselhos locais e do conselho distrital. A fala do entrevistado também revela uma contradição que está relacionada à participação popular. Fica evidenciado, através dos relatos, que a participação é mais dinâmica em alguns territórios, porém, em outros não o é.

\section{- Empoderamento dos usuários}

O Entrevistado 3 informou que a participação dos conselheiros no CDS é efetiva. Cada usuário traz as pautas referentes ao seu território e sai da reunião mais apropriado sobre o que reivindicar, a que órgãos reivindicar e apto a contribuir com essas informações no seu território. O DS onde o entrevistado atua conta com a presença dos trabalhadores não só do DS e das Unidades de Saúde da Família (USF) em sua reunião, mas de trabalhadores de outras instituições, como dos Centros de Especialidades e Hospitais Municipais, discutindo, assim, o território de saúde, e não apenas a sede do Distrito. Cada um dos equipamentos sociais de saúde possui sua representação no Conselho. Além disso, a maioria das pautas é trazida pelos usuários, o que é apontado pela representante do DS como consequência da presidência do conselho ser composta por um representante da sociedade civil.

O termo "empowerment", que em bom português pode ser traduzido como empoderamento, pode ser definido pelo menos de duas maneiras, de acordo com Maria da Glória Gohn. A referida autora caracteriza o empoderamento como: "Processos de mobilizações e práticas destinadas a promover e impulsionar grupos e comunidades no sentido de seu crescimento, autonomia, melhora gradual e progressiva de suas vidas [...]" (GOHN, 2004, p. 23). Sendo assim, o empoderamento dos usuários dos CDS(s) faz com que essas pessoas percebam que são possuidoras de direitos e que podem e devem lutar para concretizá-los. Quando eles passam a entender os mecanismos de funcionamento dos organismos institucionais de saúde e aprendem a reivindicar as suas demandas, as chances de serem ouvidos e atendidos são muito maiores.

“Temos que nos abrir para a participação popular, eu não consigo entender gestão sem participação popular. Não tem como fazer. Só com a gestão e o trabalhador não vai acontecer discussão nem problematização de absolutamente nada." (Entrevistado 3).

Chaves et al., (2014) salientam que a construção coletiva de espaços de discussão e reflexão conjunta pode ser entendido como ambiente singular de formação de indivíduos capazes de fazer história e transformar a sociedade. Já de acordo com Carvalho (2004), é possível encontrar caminhos para o empoderamento da comunidade quando se reconhece o direito da população de participar e opinar sobre as decisões que afetaram diretamente a sua vida e da sua comunidade.

- A mobilização coletiva e individual para a criação de Conselhos Locais

De acordo com o Entrevistado 4, em menos de dois anos, o número de CLS existente nos territórios cobertos por seu Distrito passou de 1 (um) para 6 (seis).

"Eu entrei no distrito sanitário IV em 2013 na gestão do atual prefeito, e só havia 1 (um) conselho local de saúde, que era o da Ilha. Hoje, nós já estamos com seis CLS(s) formados. Formamos o do Varadouro, Ipês, Distrito Mecânico, Jaguaribe (como fazia parte do Distrito Sanitário 1, já era um conselho local, mas não estava formalizado, então a gente conseguiu formalizar agora) e formamos o do Roger. Então, passou de um para seis CLS(s) em dois anos." (Entrevistado 4). 
Assim, em sua visão, o funcionamento dos CDS(s) contribui na mobilização das pessoas e dos coletivos atuantes no distrito no sentido de se voltarem às realidades particulares de seus territórios e organizarem processos locais de participação. Um dos fatores que, possivelmente, pode explicar essa mobilização é o entendimento dos conselhos como espaços mais sensíveis às demandas comunitárias. Instâncias de participação que estão localizadas geralmente no território da comunidade, assim, muito mais próximas do cotidiano das pessoas e da dinâmica real dos serviços de saúde (LISBOA et al., 2016).

De acordo com as entrevistas, está sendo elaborado um instrumento de monitoramento desses CLS(s), conforme ocorrem as reuniões de CDS, como forma de acompanhamento das pautas e demandas das reuniões territoriais, ainda que se trate de uma reunião menos formal e que não precise de paridade.

As vivências - tidas pela referida entrevistada enquanto profissional do serviço básico de saúde, no tocante à criação e participação em espaços de conversa cuja pauta permanente eram as questões de saúde do território - foram percebidas como uma contribuição para efetivação dos resultados relativos aos CLS(s) do respectivo distrito.

"Na época que eu estava nas unidades, no Varadouro, eu fui enfermeira em 2001, a gente conseguiu assim formar [o que] na época não se chamava CLS, mas a gente dizia que era uma equipe que discute saúde, um grupo, e aí a gente juntava o padre, líder de associação, agente de saúde, o LATATA, o que tivesse lá e sempre a gente estava discutindo as coisas da saúde em coletivo" (Entrevistado 4).

Outro aspecto que contribui no trabalho de fomento à participação social é a organização presente nas ações e objetivos a serem alcançados pelo DS em questão, pois há um planejamento antecipado dos mesmos. É feito calendário e formulação de metas a serem atingidas dentro de prazos estabelecidos, de modo que todos, em prol de um objetivo comum, buscam sua realização. Foi neste modelo que, em pouco tempo, se obteve um aumento significativo na quantidade de CLS nas comunidades vinculadas a esse distrito.

\section{Considerações em torno dos obstáculos e potencialidades}

Quando nos propusemos a fazer uma reflexão sobre a participação social nos CDS(s), foi possível identificar a conexão dialética que estava presente nesse fenômeno social com suas contradições e mediações, e dessa forma, descobrir suas determinações e refletir sobre elas, na perspectiva de contribuir para o aprofundamento da discussão sobre a participação social e as formas de estimulá-la e assegurá-la. São elementos que fazem parte do processo de construção das práticas participativas, sobretudo em contextos onde a população encontra limites para participar do gerenciamento dos serviços públicos, como é o caso em muitas regiões do Brasil. Esses elementos precisam ser problematizados para que possam ser compreendidos pelos sujeitos que estão diretamente envolvidos no processo, para, assim, criar possibilidades de transformação da realidade.

A análise desenvolvida permitiu-nos identificar contradições contidas nas respostas dos entrevistados que são destacadas através dos obstáculos e das potencialidades, assim como, também, perceber que, de acordo com o princípio da totalidade, a participação social nos CDS(s) está condicionada por uma série de determinações sociais que podem envolver o contexto sociocultural, os usuários e as equipes de saúde. 
Observou-se que, na percepção dos entrevistados, ainda é significativamente desafiador assegurar uma expressiva participação dos profissionais da saúde e dos próprios usuários nos CDS(s). Dentre os fatores que justificam essa compreensão, temos elementos como a fragilidade da compreensão de alguns desses indivíduos quanto ao entendimento do conselho como um espaço que abriga um potencial transformador e de ampliação da cidadania. Jacobi (2002) salienta que a indiferença e a subestimação são barreiras que precisam ser superadas para que as práticas participativas possam ser enxergadas como uma nova qualidade de cidadania, onde as pessoas tenham seus direitos respeitados e possam criar novos espaços de participação sociopolítica. Desta forma:

A participação popular se transforma no referencial de ampliação das possibilidades de acesso dos setores populares dentro de uma perspectiva de desenvolvimento da sociedade civil e de fortalecimento dos mecanismos democráticos, mas também de garantia da execução eficiente de programas de compensação social no contexto das políticas de ajuste estrutural e de liberalização da economia e de privatização do patrimônio do Estado. (JACOBI, 2002, p. 444).

Assegurar a participação social, através de mecanismos como conselhos de saúde, contribui, em alguma medida, para o desenvolvimento da sociedade e para o fortalecimento da democracia, pois o exercício participativo no cotidiano dos contextos locais (inclusive nos serviços) é também formativo e proporciona processos de ensino e aprendizagem que fomentam uma cultura mais participativa e de maior envolvimento dos usuários com a dinâmica de organização dos processos de atenção à saúde. No entanto, é preciso reconhecer que o contexto social guarda muita complexidade e em alguns casos,

as propostas participativas ainda permanecem mais no plano da retórica do que na prática. Poucas são, de fato, as experiências de gestão municipal que assumem uma radicalidade democrática na gestão da coisa pública, assim como ampliam concretamente o potencial participativo. (JACOBI, 2002, p. 444-445).

Esse aspecto, juntamente com uma cultura política preponderantemente pouco participativa, pode estar relacionado com a fragilidade percebida pelos relatos dos participantes da pesquisa quanto à participação dos usuários, bem como com a visão relativamente pessimista que identificamos sobre o potencial dos conselhos. Porém, essas questões não podem tornar-se obstáculos permanentes e intransponíveis. É preciso pensar estratégias de superação para que os conselhos funcionem como espaços para a manifestação das necessidades do coletivo.

Por outro lado, em que pesem tais desafios, também foi possível constatar que, na visão dos entrevistados, os CDS(s) constituem um espaço profícuo para a promoção e construção de uma outra cultura de participação da comunidade na dinâmica dos serviços de saúde. Ou seja, é um espaço provocativo de mudanças diante das fragilidades anteriormente citadas.

Os CDS(s) são percebidos por alguns entrevistados como um espaço favorável para a discussão, reflexão e aprendizagem. Quando acontece de forma dinâmica, constante e com discussões de conteúdos atinentes à resolução de problemas concretos, a participação da comunidade nos CDS(s) conflui para um maior entrosamento entre o usuário e os membros das equipes dos serviços de saúde. As pessoas da comunidade podem se sentir mais à vontade para expor suas demandas e insatisfações. Nesse contexto de diálogo e escuta, também pode ser possível ao usuário compreender com mais clareza os mecanismos de funcionamento do SUS e, assim, aprender a reivindicar para que o serviço público se adeque às necessidades da comunidade. 
As aprendizagens propiciadas pelo encontro e pelo compartilhamento de saberes fazem do CDS e do CLS espaços educativos e de formação cidadã. Assim, constrói-se o empoderamento dos usuários na medida em que vão refletindo e problematizando sobre sua própria realidade. Como salientam Busana et al.(2015), a participação ativa da população tem o potencial de melhorar a autoestima e fazer com que as pessoas se sintam úteis, integrantes essenciais de um coletivo. Ainda conforme estes autores, é possível afirmar que:

É através da participação popular nos conselhos de saúde, aliada à vontade de realizar transformações políticas e sociais, que este processo se constituirá em ferramenta essencial para o desenvolvimento do empoderamento individual e coletivo, uma vez que tal processo modifica o status quo ao promover uma consciência política e suscitar autonomia para a tomada de decisão. (BUSANA et al., 2015, p. 447).

Enquanto potencialidade que pode ser desenvolvida no âmbito da participação nos conselhos, a construção do empoderamento dos usuários é um processo importante para o desenvolvimento de sua capacidade de pensar por conta própria e com responsabilidade, expor o seu ponto de vista e verbalizar os seus desejos e necessidades. Sendo mobilizados a lutar pelo bem comum, para que todos possam alcançar melhores condições de vida e exercer de forma plena sua cidadania. No que se refere ao empoderamento conquistado através da participação popular, há mais a observar. De acordo com Carvalho e Gastaldo (2008) é

[...] um processo que conduz à legitimação e dá voz a grupos marginalizados e, ao mesmo tempo, remove barreiras que limitam a produção de uma vida saudável para distintos grupos sociais. Indica processos que procuram promover a participação social visando ao aumento do controle sobre a vida por parte de indivíduos e comunidades, à eficácia política, a uma maior justiça social e à melhoria da qualidade de vida. Espera-se, como resultado, o aumento da capacidade dos indivíduos e coletivos para definirem, analisarem e atuarem sobre seus próprios problemas através da aquisição de habilidades para responder aos desafios da vida em sociedade. (p. 2032).

O aumento da capacidade de atuação das pessoas, que pode ser considerado um fruto do seu exercício na direção do empoderamento, também contribui para sua mobilização, sobretudo no que diz respeito à criação de novos espaços de conselhos e outros cenários favoráveis à expressão da participação popular, sendo essa outra potencialidade apontada pelos entrevistados do estudo.

Em nossa análise, essa constatação significa que esses sujeitos acreditam no conselho e na sua potencialidade como estratégia para construir novas formas de relação propositiva e colaborativa com os serviços de saúde. Nesse sentido, a presença dos conselhos na comunidade representa a possibilidade de discutir sobre os problemas reais que fazem parte do cotidiano e, muitas vezes, só são sentidos com maior intensidade pela população comunitária.

\section{Conclusões}

A promoção de entrevistas com atores estratégicos dos DS sobre a cena de participação social em saúde do município de João Pessoa foi de suma importância. O principal obstáculo observado consiste na quantidade e na qualidade da participação dos usuários nas reuniões, considerando que não são todos os movimentos e entidades que se fazem presentes nesse espaço, 
por não acreditarem, segundo relatam em depoimentos informais as pesquisadoras, que tal participação seja capaz de gerar mudanças.

Por isso, é importante que os usuários sejam orientados sobre a importância desses espaços e, assim como realizado em alguns DS pesquisados, levar experiências exitosas de outros territórios como forma de ilustrar conquistas alcançadas a partir dos Conselhos Distritais.

Além da dificuldade de participação e de interesse de alguns membros da sociedade civil, há fragilidade de envolvimento de algumas classes de profissionais, como a médica, que não manifesta, em sua maioria, interesse em participar do espaço de discussão dos CDS, ficando a representatividade dos profissionais de saúde restrita, principalmente, aos Agentes Comunitários de Saúde e Enfermeiros.

Foi possível observar também, a partir das visitas e entrevistas, que alguns conselheiros representam interesses particulares, levando demandas individuais ou de grupos específicos, defendendo apenas os interesses restritos a determinado conjunto de pessoas, não priorizando demandas coletivas e a mobilização conjunta para determinação de estratégias que contribuam para a sociedade como um todo.

Por outro lado, a rotatividade presente no âmbito da gestão e profissionais dos DS devido à entrada e saída de gestores estaduais e/ou municipais é um dos fatores que impactam negativamente o processo de trabalho e o fortalecimento de vínculo entre os usuários/entidades/ movimentos componentes dos CDS e CLS e a gestão do serviço. Dado que esses contratados estabelecem sua própria dinâmica de trabalho no decorrer do exercício de suas atribuições, e a própria comunidade (e CLS) se familiariza com essa dinâmica, há uma desestabilização quando os mesmos são substituídos "repentinamente", depois que outros gestores são eleitos, refazendo, muitas vezes, o quadro de servidores em sua maioria.

Durante as cinco entrevistas realizadas nos DS da capital paraibana, foi possível ouvir que as pessoas da comunidade não acreditam ou não se interessam pela participação. Isso pode se dar pela complexidade real de compreender o SUS, pela falta de informação a respeito do que realmente propõe o CDS, seja pela rotatividade dos profissionais e gestão, pela dificuldade natural que as pessoas têm de se fazerem presentes nos espaços de participação, ou mesmo pela própria fragilidade nas estratégias pedagógicas utilizadas pela gestão.

Além disso, a tenuidade do sistema relativo à participação social também permeia as pautas de discussões nas reuniões de CDS, uma vez que conselhos cujas reuniões já vêm acontecendo há um tempo considerável dedicam suas reuniões para tratar de assuntos ligados ao funcionamento e políticas de controle social, quando, na verdade, deveriam ser espaços onde a gestão escuta e registra as demandas apresentadas pelos comunitários e, com eles, buscam construir caminhos para mudança daquela realidade problemática.

Contudo, o número de conselhos locais tem aumentado nos últimos anos, e a gestão tem se preocupado em informar e orientar os membros dos CLS e dos CDS(s) quanto a questões introdutórias da participação social, uma vez que a complexidade do funcionamento e regimento destes conselhos dificulta o entendimento dos usuários sobre a dinâmica e objetivo do espaço.

\section{Referências}

ACIOLE, G. G. Algumas questões para o debate do controle social no sistema único de saúde. Revista Saúde em Debate, jan-abr 2003. 
ALENCAR, I.C. ; CRUZ, P. J. S. C. . Educação popular e participação local em saúde: situações-limites e inédito-viáveis. In: MELO NETO, J. F.; CARTAXO, C.J.; ARAÚJO, L.M. de; CRUZ, P.J.S.C. (Org.). II Seminário Nacional de Pesquisa em Extensão Popular Pesquisa em Extensão Popular: que referenciais? Anais. 1ed. João Pessoa: Editora da UFPB, 2013, v. 1, p. 133-149.

BRASIL. Lei 8.142/1990. Disponível em: http://conselho.saude.gov.br/legislacao/lei8142_281290.htm. Acesso em: 04 mai. 2018.

BRASIL. Ministério da Saúde. Secretaria de Atenção à Saúde. Departamento de Atenção Básica. Política Nacional de Atenção Básica. Brasília: Ministério da Saúde, 2012.

BUSANA, J.A.; HEIDEMANN, I.T.S.B.; WENDHAUSEN, A.L.P. Participação popular em um conselho local de saúde: limites e potencialidades. Texto Contexto Enferm. 2015.

CAMARGO JR., Kenneth R. de; BOSI, M. L. M. Editorial: Metodologia qualitativa e pesquisa em saúde coletiva. Physis: Revista de Saúde Coletiva, Rio de Janeiro, v. 21, n. 4, Dec. 2011.

CARVALHO, S.R. As contradições da promoção à saúde em relação à produção de sujeitos e a mudança social. Ciência \& Saúde Coletiva, v. 9, n. 3: 669-678, 2004.

CARVALHO, S.R; GASTALDO D. Promoção à saúde e empoderamento: uma reflexão a partir das perspectivas crítico-social e pós-estruturalista. Ciênc. Saúde Coletiva, 2008.

COELHO, J. S. Construindo a Participação Social no SUS: um constante repensar em busca de equidade e transformação. Saúde Soc. São Paulo, v. 21, supl. 1, p. 138-151, 2012.

CHAVES, L. et al. Curso "Participação popular, movimentos sociais e direito à saúde": uma experiência de educação popular em Saúde na Bahia a partir do MobilizaSUS. Interface (Botucatu), v. 18, supl. 2: 1507-1512, 2014. Disponível em: <http://www.scielo.br/scielo.php?script=sci_arttext\&pid=S141432832014000601507\&lng=en\&nrm=iso>. Acesso em: 07 dez. 2018.

FERNANDES, V.C. Estratégias de mobilização para a participação comunitária de conselheiros municipais de saúde. Tese (doutorado) - Universidade Estadual Paulista. Botucatu, 2019.

GADAMER, H.-G. Verdade e Método. Petrópolis: Vozes, 1999.

GOHN, M. G. Conselhos gestores e participação sociopolítica. São Paulo: Cortez, 2001.

GOHN, M. G. Empoderamento e participação da comunidade em políticas sociais. Saúde e Sociedade, v. 13, n. 2, p. 20-31, 2004.

HOLLIDAY, O. J. Para Sistematizar Experiências. 1ํㅗㄹ ed. João Pessoa: Editora Universitária UFPB. 1996. v. 1.213p.

JACOBI, P. R. Políticas sociais locais e os desafios da participação citadina. Ciência \& Saúde Coletiva, 7(3):443-454, 2002.

KRUGER, T. R. O desconhecimento da reforma sanitária e da legislação do SUS na prática do conselho de saúde. Planejamento e Políticas Públicas-IPEA, n. 22, p. 119-144, 2000. Disponível em: http:// www.ipea.gov.br/ppp/index.php/PPP/article/view/82/162. Acesso em 04 mai. 2018.

LABRA, M. E. Conselhos de Saúde: dilemas, avanços e desafios. In: LIMA, N. T (Org.). Saúde e Democracia. Rio de Janeiro: Fiocruz, 2005. p. 353-384.

LISBOA, E. A.; SODRÉ, F.; ARAÚJO, M. D.; QUINTANILHA, B. C.; LUIZ, S. G. Conselhos locais de saúde: caminhos e (des)caminhos da participação social. Trab. Educ. Saúde, Rio de Janeiro, v. 14. set./dez. 2016. 
MARTINS, P. C.; COTTA, R. M. M.; MENDES, F. F.; FRANCESCHINNI, S. C. C.; PRIORE S. E.; DIAS G.; BATISTA, R. S.. Conselhos de Saúde e a Participação Social no Brasil: Matizes da Utopia. Physis Revista de Saúde Coletiva, Rio de Janeiro, 18 [ 1 ]: 105-121, 2008. Disponível em: http://www.redalyc.org/ html/4008/400838215007/ Acesso em 04 de Mai. 2018.

MELO NETO, J. F. Dialética: uma visão marxista. In: MELO NETO, J. F.; CEZARINO, H.; CARNEIRO, G. M. (Org.). Dialética. 1. ed. João Pessoa: UFPB, 2002. p. 83-121.

MELO NETO, J.F..Heráclito: um diálogo com o movimento. João Pessoa - PB: Editora da Universidade Federal da Paraíba, 1996 (Ensaio).

MINAYO, M.C.S. O desafio do conhecimento: pesquisa qualitativa em saúde. 11a ed. São Paulo, HUCITEC, 2008.

NOGUEIRA, F.C.P.; LIMA, L.H.O.; WOLFOVITCH, R.G.S.; NASCIMENTO, S.M.; LOPES, S.R.M. Implantação de um conselho local de saúde: desafios da prática do controle social. Revista Baiana de Saúde Pública, 2008.

OLIVEIRA, M. W. de. Pesquisa e trabalho profissional como espaços e processos de humanização e de comunhão criadora. Cad. CEDES [online]. 2009, vol.29, n.79, pp.309-321.

SILVA, P.B.G.; ARAUJO-OLIVERA, S.S. Cidadania, ética e diversidade: desafios para a formação em pesquisa. Trabalho apresentado no 6. Encuentro Corredor de las Ideas del Cono Sur "Sociedad civil, democracia e integración", Montevideo, 2004.

VALLA, V. V. Sobre participação popular: uma questão de perspectiva. Cadernos de Saúde Pública, Rio de Janeiro, v. 14, p. 7-18, 1998. Suplemento 2. 